\title{
Trends and determinants of suicide in Warangal District Telangana, India: six years retrospective study based on secondary data
}

\author{
Suchita Rawat ${ }^{1}$, Pooran Chand Joshi', Maroof Ahmad Khan ${ }^{2}$ and Kallur Nava Saraswathy ${ }^{1 *}$
}

\begin{abstract}
Background: Suicide is a major public health concern resulting in premature deaths. The six years (2010-2015) retrospective study on suicide cases reported at a tertiary care center of Warangal district, Telangana, India aims to explore the trend and determinant of suicide.

Results: Suicide was predominant among $35-<45$ years aged males and females aged $18-<30$ years. The suicide method varied, males preferred self-poisoning while female committed suicide by self immolation. Among males a summer peak while spring peak was observed for Non-Violent and violent methods respectively. The suicide in females peaked in autumn for non-violent method while Violent suicide was observed in summer. The Joinpoint regression analysis found no significant change in the suicide rate from time period (2010-2015) in overall population or stratification by gender for Warangal district, Telangana India.

Discussion: Suicide prevention strategies or interventions in the studied area could be initiated using the baseline data obtained during present study.
\end{abstract}

Keywords: Suicide, Poisoning, Self immolation, Suicide seasonality

\section{Background}

Suicide account for nearly 8 lakh deaths annually worldwide (WHO Official website, 2018a). It is the second-leading cause of premature death among 1529 years age cohort and triggers huge economic, social and psychological burden on families, communities, and countries (WHO Official website, 2018a). Compared to other regions of the world suicide is highest in the South-East Asia region (World Health Organization. Preventing suicide: A global imperative, 2014). It is estimated that $84 \%$ of the suicides occur in Middle and Low-income countries of which India and China alone contribute to half the suicide (Phillips \& Cheng, 2012). The suicide rate of India spans from 11.2 per100, 000 population to 189.9 per100, 000 population (Jordans et al., 2014) and has augmented by $17.3 \%$ over the past

\footnotetext{
* Correspondence: knsaraswathy@yahoo.com

'Department of Anthropology, University of Delhi, Delhi 110007, India

Full list of author information is available at the end of the article
}

decade (2005-2015) (National Crime Records Bureau of the Ministry of Home Affairs, Government of India, Report on Accidents and Suicides in India (2010-2015), 2018). In India regional disparity in suicide is witnessed, majority aggregated within Southern state of India (Patel et al., 2012). Telangana is the 29th state of India, constituted under the Andhra Pradesh Reorganization Act 2014. The state encompass an area of 1.21 lakh square kilometers and population size of 351.94 lakh (177.04 lakh male and 174.90 lakh females) (Census of India, 2018). In comparison to other states of India, Telangana recorded 4th highest suicide rate; 26.7 per100,000 population in 2014, moreover, it recorded the 3rd highest Suicide rate; 27.7 individuals per100,000 population in 2015 which is higher than four neighboring Southern States and almost double the National Suicide rate (National Crime Records Bureau of the Ministry of Home Affairs, Government of India, Report on Accidents and Suicides in India (2010-2015), 2018). The 
present study is aimed to characterize Suicide Deaths from the period of 2010-2015 by analyzing variables; Age, gender, suicide methods and seasonal variation for the suicide cases reported at a Tertiary care center located in Warangal district, Telangana, India.

\section{Methods}

Mahatma Gandhi Memorial Hospital is a 1000 bedded super specialty government hospital located at Warangal city of Telangana state, India which provides medical facilities to to residents of the Warangal district and neighboring territories.

Retrospective data (name, age, gender, residence, date of admission to hospital, date of death and cause of death) of the suicide victims admitted to the emergency ward of the hospital during the period of six years (1 January 2010 to 31 December 2015) was obtained from the medical records of Mahatma Gandhi Memorial hospital after permission from the hospital Superintendent. For data analysis, secondary data was stratified on the basis of the year, age, gender, suicide methods, type of suicide i.e. violent or non-violent and seasonality of suicide.

To determine which age group is borne upon the most by suicide, the cases were classified according to 6 age cohorts i.e. 1) <14 years 2) $14-<18$ years 3) $18-<$ 30 years 4) $30-<45$ years 5)45 $-<60$ years 6 ) $\geq 60$ years (National Crime Records Bureau of the Ministry of Home Affairs, Government of India, Report on Accidents and Suicides in India (2010-2015), 2018). The suicide methods were classified as either violent (use of firearm or shotgun, hanging, cutting and piercing with sharp objects, jumping from high places, getting run over by train or moving vehicle) or non-violent (ingestion of Pesticide, Poison by gas, Suffocation, and overdose) (Sun \& Jia, 2014).

For understanding the Seasonal variation of suicide, suicide cases were studied across four seasons i.e. winter (December, January, February), spring (March, April, May), summer (June, July, August) and autumn (September, October, November) (Coimbra et al., 2016).

The differences in the distribution of Age cohort, suicide method and seasonal variation were measured by Pearson's chi square test performed in SPSS version 20 (IBM -SPSS inc. Chicago, IL).

The crude suicide rate per 100,000 population and the trends were described using joinpoint regression analysis by determining the turning points for the 6 year period (2010-2015) using freely available software Joinpoint Regression Program, Version 4.5.0.1 (Surveillance Research program, National cancer Institute, USA) (Program, 2017). Negative Binomial regression was applied to compute Suicide relative risk (RR) and its 95\% Confidence interval explained by independent variables; year (2010 as reference), gender (Female as reference) and suicide method (Violent method as reference).

\section{Result}

One thousand three hundred twenty-five suicide cases (750 males and 575 females) over the stretch of 6 years (2010-2015) were reported from various mandals (Sub district/Taluk comprising of several village clusters) of Warangal district, Telangana, India. Five mandals; Atmakur, Geesugnda, Ghanpur (Station), Hanamkonda, Sangam reported majority of the cases while the rest cases (less than 5\%) heterogeneously distributed across the remaining Mandals located at greater distance. These cases were majorly reported from rural regions (1217 cases, 92.8\%) than compared to urban regions (95 cases, $7.2 \%)$.

Overall suicide cases were reported highest in $18-<$ 30 years age group $(34.1 \%)$ while least among $<14$ years age group $(2.4 \%)$. Female of age cohort $18->30$ years and male of 30- $>45$ years age group had elevated suicide deaths compared to other age cohorts (Table 1).

The seasonal pattern in suicide was observed i.e. maximum in summer (28\%) followed by spring $(25.5 \%)$ and autumn (25.3\%) while least in winter (21.2\%) (data not shown).

The suicide method also illustrated seasonality, among males single peak in spring and summer was observed for violent and non-violent method respectively. Among females, peak in summer and autumn was observed for violent and non-violent method respectively (Table 2).

According to method of suicide, $67.2 \%$ of the cases committed suicide by poisoning, $31.1 \%$ by self immolation and $1.5 \%$ by hanging. Gender difference for suicide methods was observed, $82.6 \%$ of males preferred poison while $50.6 \%$ females succumbed to self immolation (Table 3). Within diverse range of poisons, keratolytics hair treatment preparation $(4.8 \%$ females versus $1 \%$ males) and herbicides or fungicides (20.7\% females versus $16 \%$ males) illustrated female predominance while in pesticide poisoning male predominance was observed (51.7\% females versus $61.2 \%$ Males) (Table 3 ).

The suicide rate during the six years time frame (2010-2015) ranged 3.67 to 8.40 for overall population, for males ranged from 3.87 to10.40 while crude rate ranged from 3.48 to 7.13 for females (Table 4). No significant difference in the trends (no significant change in annual percentage change and zero joinpoint) over the six years time frame was obtained in the Joinpoint regression analysis (Figs. 1, 2 and 3). The relative risk of suicide increased 1 fold (non-significant) for year 2014 and 2015 compared to 2010.Furthermore 2 fold (non significant) for poisoning cases than compared to hanging or self-immolation while no relative risk for gender was observed (Table 5). 
Table 1 Age wise distribution of suicide cases

\begin{tabular}{lllll}
\hline Age cohort & Total & Male & Female & Perason's Chi Square pvalue \\
\hline $1 .<14$ years & $32(2.4 \%)$ & $18(2.4 \%)$ & $14(2.4 \%)$ & $38(6.6 \%)$ \\
2. $14<18$ years & $54(4.1 \%)$ & $16(2.1 \%)$ & $263(45.7 \%)$ & $P<0.001$ \\
$3.18-<35$ years & $452(34.1 \%)$ & $189(25.2 \%)$ & $147(25.6 \%)$ & $64(11.1 \%)$ \\
4. $35-<45$ years & $422(31.8 \%)$ & $275(36.7 \%)$ & $49(8.5 \%)$ & \\
$5.45-<60$ years & $219(16.5 \%)$ & $155(20.7 \%)$ & $97(12.9 \%)$ & \\
$6 . \geq 6$ years & $146(11 \%)$ & &
\end{tabular}

Percentages calculated across column, Agecohort according to NCRB ADSI report

\section{Discussion}

Suicide defined by renowned Clinical Psychologist and Suicidologist Edward. S. Schneidman as "the conscious act of self-induced annihilation, best understood as a multidimensional malaise in a needful individual who defines an issue for which the suicide act is perceived as the best solution" (Masango et al., 2008). WHO (World health organization) has recognized suicide as public health concern and aims at 10\% decrease in the burden of Suicide by 2020 (WHO Official website, 2018a). Suicide rate diverge for countries due to the difference in the social and cultural background, availability of mental health services, classification of death and accurate registration of suicidal deaths (Hawton \& Heeringen, 2009). Globally suicide rate varies from 1.66 per100,000 population to 36.2 per100,000 population (ElHak et al., 2009; Naidoo \& Schlebusch, 2014; Sun et al., 2013) and for Indian states it varies from 11.8 per100,000 population to 82.2 per100,000 population (Mohanty et al., 2007; Kumar et al., 2013; Badiye et al., 2014). Suicide rate 8.4 per100,000 population of Warangal district, Telangana observed in the present study seems to be much below suicide rate reported by other Indian studies.This could be due to difference in the source, suicide data was collected from only one tertiary care from Warangal district and hence undermines the true picture of the entire Warangal district. Another reason could be the misclassification of suicide deaths as either unintentional or accidental death for poisoning cases.
Furthermore among women due to the legal issues associated with Dowry death or death of women within 7 years of marriage suicide could be underreported (Patel et al., 2012). The Mental Health Care Bill introduced in the Rajya Sabha in August 2013 was passed recently in 2016 which decriminalized Suicide attempt and directed the government to provide rehabilitation to such individuals in order to thwart future reattempt (Rao et al., 2016). This would certainly improve the current scenario of both underreporting of Suicide and its associated psychological or economic burden on Suicide attempter and his family.

In the present study the temporal trend over six years timeframe from 2010 to 2015 showed an increase in overall suicide cases. As per unofficial records, during the struggle of Telangana for a separate statehood, political driven suicides were witnessed (Official website India today, 2018; Official website Newyork times, 2018) which would have added to the incidence of suicide during the studied time frame. Furthermore an elevated suicide incidence in a rural area than compared to the urban area of Warangal district was observed. This observation is in concordance with studies conducted across various geographical regions i.e. Maharashtra (Batra, 2003), Orissa (Sharma et al., 2007) and Sikkim (Chettri et al., 2016). 17\% of total famer suicide in India, 1358 cases reported from Telangana state was corollary of Bankruptcy or indebtedness, farming related issues, prolonged illness and family problems (National Crime

Table 2 Seasonal distribution of violent and non-violent Suicide method

\begin{tabular}{|c|c|c|c|c|c|}
\hline \multirow[t]{2}{*}{ Group } & \multicolumn{4}{|l|}{ Season } & \multirow{2}{*}{$\begin{array}{l}\text { Perason's Chi } \\
\text { Square } p \text { value }\end{array}$} \\
\hline & Winter & Spring & Summer & Autumn & \\
\hline$\overline{\text { Male }}$ & & & & & $P=0.015$ \\
\hline Nonviolent & 112 (18.2\%) & $156(25.3 \%)$ & $183(29.7 \%)$ & 165 (26.8\%) & \\
\hline Violent & $32(24.4 \%)$ & 45 (34.4\%) & $31(23.7 \%)$ & $23(17.6 \%)$ & \\
\hline \multicolumn{6}{|l|}{ Female } \\
\hline Nonviolent & 53 (19.6\%) & 57 (21.1\%) & 72 (26.7\%) & 88 (32.6\%) & $P=0.002$ \\
\hline Violent & 83 (27.3\%) & 79 (26\%) & $84(27.6 \%)$ & 58 (19.1\%) & \\
\hline
\end{tabular}

Percentages calculated across row, Season defined according to Coimbra et al. 2016 
Table 3 Distribution of Suicide Method

\begin{tabular}{|c|c|c|c|c|}
\hline Suicide Method & Total & Male & Female & Perason's Chi Square $p$ value \\
\hline 1)Self immolation & $415(31.1 \%)$ & $124(16.5 \%)$ & $291(50.6 \%)$ & $P<0.001$ \\
\hline 2)Hanging & $20(1.5 \%)$ & $7(\% 0.9)$ & $13(2.3 \%)$ & \\
\hline 3)Poisoning (All Types) & $890(67.2 \%)$ & $619(82.6 \%)$ & $271(47.1 \%)$ & \\
\hline \multicolumn{5}{|l|}{ Poisons Classification: } \\
\hline a) Keratolytics, keratoplasty, hair treatment drugs and preparations & $19(2.1 \%)$ & $6(1 \%)$ & $13(4.8 \%)$ & \\
\hline b) Unspecified drugs Medicaments and Biological substances & $10(1.1 \%)$ & $7(1.1 \%)$ & $3(1.1 \%)$ & $P<0.001$ \\
\hline c) Corrosive acids and acid-like substances & $13(1.5 \%)$ & $8(1.3 \%)$ & $5(1.8 \%)$ & \\
\hline d) Herbicides and fungicides & $155(17.4 \%)$ & $99(16 \%)$ & $56(20.7 \%)$ & \\
\hline e) Unspecified pesticides & $519(58.3 \%)$ & $379(61.2 \%)$ & $140(51.7 \%)$ & \\
\hline f) Unspecified substances & $174(19.6 \%)$ & $120(19.4 \%)$ & $54(19.9 \%)$ & \\
\hline
\end{tabular}

Percentages calculated across column

Records Bureau of the Ministry of Home Affairs, Government of India, Report on Accidents and Suicides in India (2010-2015), 2018). Further, it is speculated that some of the farmers who entered modernized agriculture are weak in dealing and coping with the institutional channels of modernization without effective access to services like insurance, warehousing, post-harvest processing etc (Mohanty, 2013) Since majority of the rural population in Warangal district is primarily engaged in agricultural based activities (Census of India, 2018) the

Table 4) Crude and Modeled Suicide rate per 100,000 population calculated using Joint Point Regression model

\begin{tabular}{|c|c|c|c|c|}
\hline Group & $\begin{array}{l}\text { Observed Crude rate } \\
\text { (per 100,000 population) }\end{array}$ & Standard Error & $\begin{array}{l}\text { Modeled crude rate } \\
\text { (per 100,000 population) }\end{array}$ & $\begin{array}{l}\text { Annual percentage change (APC) } \\
\text { [Number of Joinpoint] }\end{array}$ \\
\hline \multicolumn{5}{|l|}{ Overall } \\
\hline 2010 & 7.77 & 0.47 & 5.73 & $\begin{array}{l}2010-2015 \text { APC }=5.46 \\
{[0 \text { joinpoint }]}\end{array}$ \\
\hline 2011 & 4.78 & 0.37 & 6.05 & \\
\hline 2012 & 4.67 & 0.36 & 6.38 & \\
\hline 2013 & 3.67 & 0.32 & 6.72 & \\
\hline 2014 & 8.43 & 0.49 & 7.09 & \\
\hline 2015 & 8.40 & 0.49 & 7.48 & \\
\hline \multicolumn{5}{|l|}{ Male } \\
\hline 2010 & 8.41 & 0.69 & 6.02 & $\begin{array}{l}2010-2015 \text { APC }=8.67 \\
{[0 \text { joinpoint }]}\end{array}$ \\
\hline 2011 & 5.00 & 0.53 & 6.54 & \\
\hline 2012 & 5.23 & 0.55 & 7.11 & \\
\hline 2013 & 3.87 & 0.47 & 7.72 & \\
\hline 2014 & 9.72 & 0.74 & 8.39 & \\
\hline 2015 & 10.40 & 0.77 & 9.12 & \\
\hline \multicolumn{5}{|l|}{ Female } \\
\hline 2010 & 7.13 & 0.64 & 5.47 & \\
\hline 2011 & 4.56 & 0.51 & 5.55 & $\begin{array}{l}\text { 2010-2015 APC }=1.40 \\
{[0 \text { joinpoint }]}\end{array}$ \\
\hline 2012 & 4.11 & 0.48 & 5.63 & \\
\hline 2013 & 3.48 & 0.45 & 5.71 & \\
\hline 2014 & 7.13 & 0.64 & 5.78 & \\
\hline 2015 & 6.39 & 0.60 & 5.87 & \\
\hline
\end{tabular}




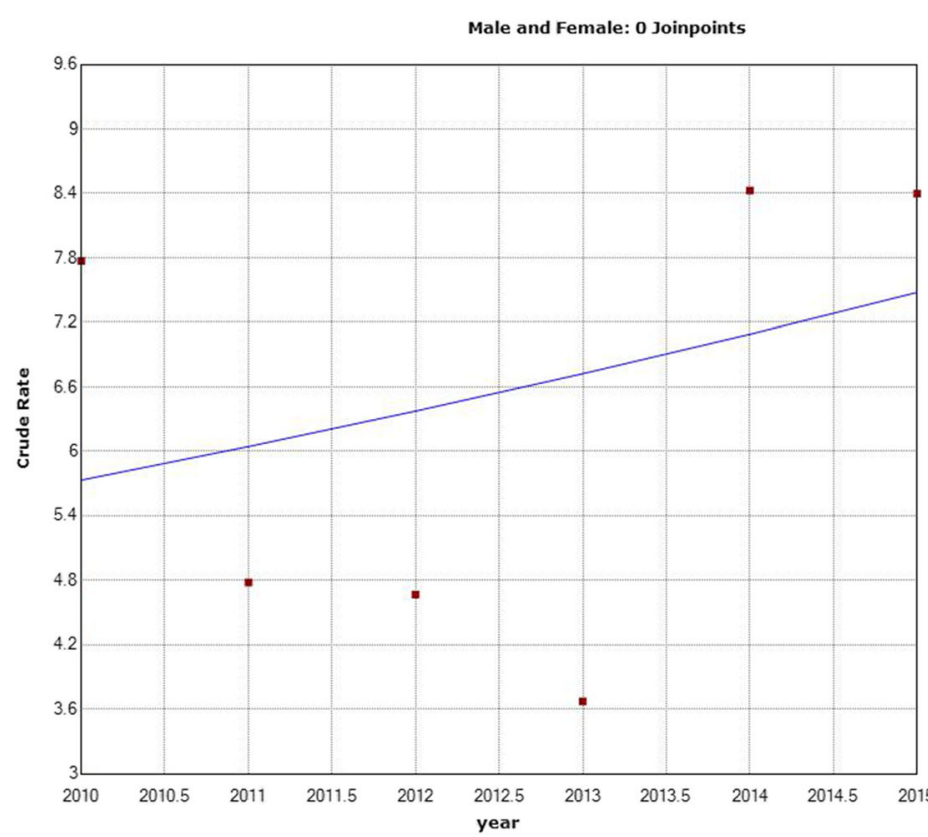

\section{二 ${ }_{2010.0-2015.0 A P C}^{\text {Oberved }}=5.46$}

Fig. 1 Fitted segment lines of Overall annual suicide rate per 100,000 population using Joinpoint regression models. $\wedge$ Indicates that the Annual Percent Change (APC) is significantly different from zero at the alpha $=0.05$ level. Final Selected Model: 0 Jointpoints

higher rural suicide reported in the present study could be due to the agrarian crisis. The Telangana government has proposed a hike in compensation from 1.5 lakh to 6 lakh for families of farmer suicide (Official website NDTV, 2018) which could have resulted in better reporting of suicide cases from rural region of Warangal district, Telangana. Another possible reason for higher suicide cases in rural region could be to the dearth of immediate medical interventions or specialized medical staff required to deal with self harm or suicide attempt case (Patel et al., 2012).

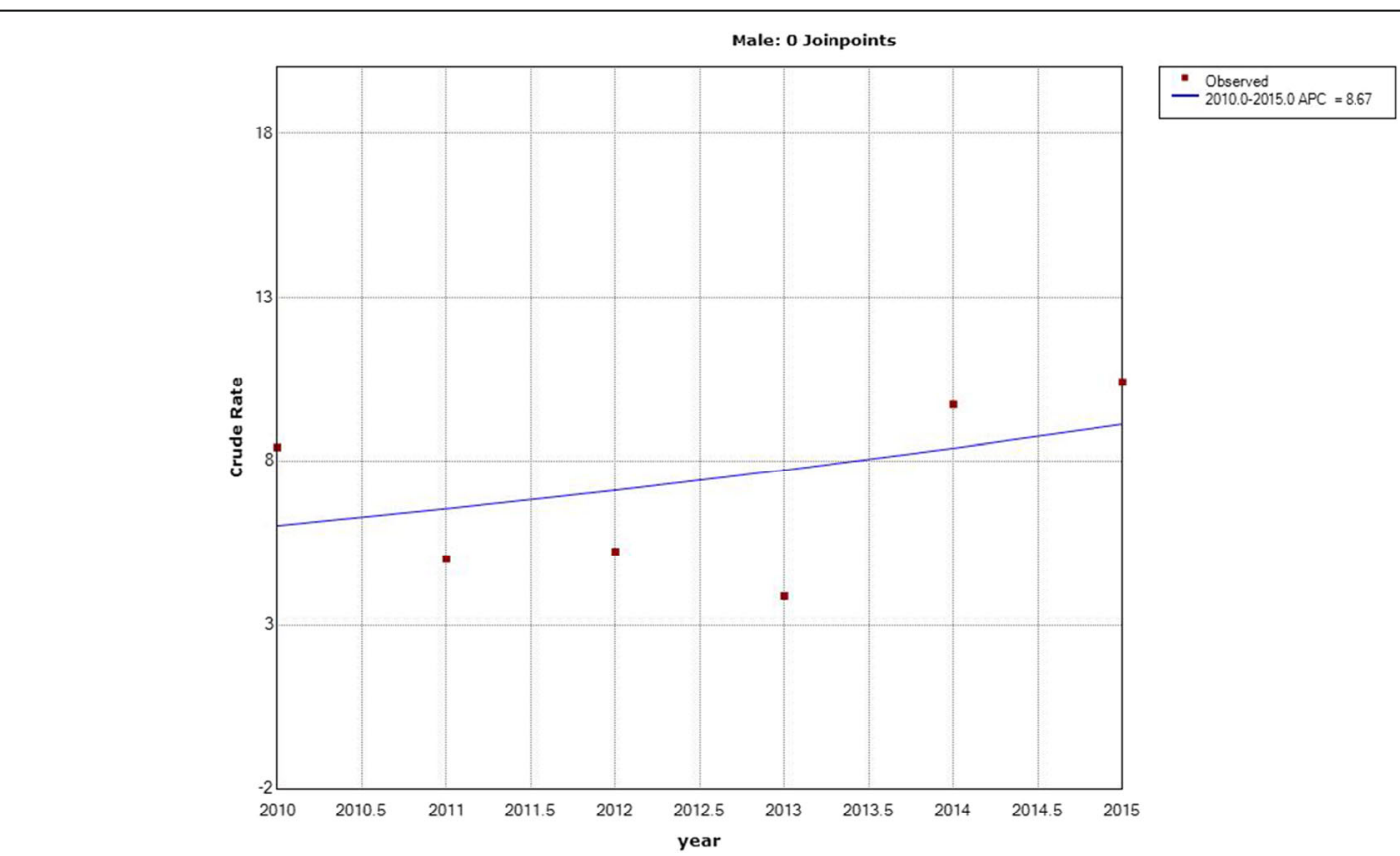

Fig. 2 Fitted segment lines of Male annual suicide rate per 100,000 population using Joinpoint regression models. ^Indicates that the Annual Percent Change (APC) is significantly different from zero at the alpha $=0.05$ level. Final Selected Model: 0 Jointpoints 


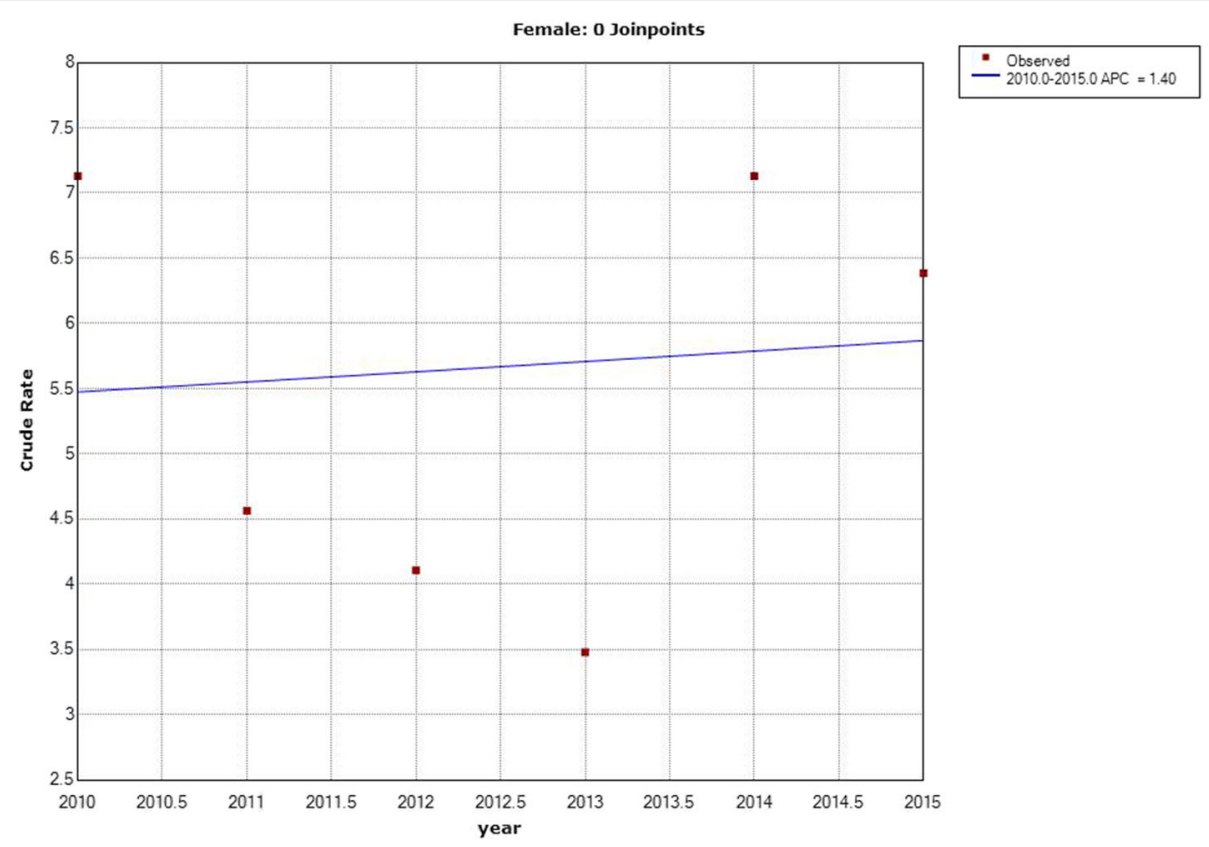

Fig. 3 Fitted segment lines of female annual suicide rate per 100,000 population using Joinpoint regression models. AIndicates that the Annual Percent Change (APC) is significantly different from zero at the alpha=0.05 level. Final Selected Model: 0 Jointpoints

The present study observation of higher suicide rate among male than compared female is in agreement with other epidemiological studies (Badiye et al., 2014; Chettri et al., 2016; Dervic et al., 2012) reporting 2-3 times higher suicide deaths among males than compared to female counterpart. The gender difference in suicide mortality could be attributed to the difference in preference of more lethal and violent suicide method (Mergl et al.,
2015), alcohol abuse and its intoxication at the time of suicide attempt (Menon et al., 2015).

The method of Suicide varies across the region of the world; hanging, use of firearms, and poisoning with drug among developed countries while pesticide self-poisoning in developing countries is preferred suicide method (Ajdacic-Gross et al., 2008). Further unique patterns such as jumping from building, charcoal self immolation,

Table 5 Negative Binomial regression model for Relative Risk (RR) (95\% Confidence Interval)

\begin{tabular}{|c|c|c|c|}
\hline \multirow[t]{2}{*}{ Group } & \multirow{2}{*}{$\begin{array}{l}\text { Descriptive Statistics } \\
\text { Number of Cases }\end{array}$} & \multicolumn{2}{|c|}{ Negative binomial regression model } \\
\hline & & $\begin{array}{l}\text { Relative Risk (RR) } \\
\text { ( } 95 \% \text { Confidence Interval) }\end{array}$ & $P$ value \\
\hline Total suicides (2010 to 2015) & 1325 & & \\
\hline 2010 & 273 & Reference & \\
\hline 2011 & 168 & $0.623(0.154-2.530)$ & 0.508 \\
\hline 2012 & 164 & $0.577(0.142-2.346)$ & 0.443 \\
\hline 2013 & 129 & $0.494(0.121-2.012)$ & 0.325 \\
\hline 2014 & 296 & $1.069(0.264-4.321)$ & 0.926 \\
\hline 2015 & 295 & $1.072(0.265-4.337)$ & 0.922 \\
\hline \multicolumn{4}{|l|}{ Gender } \\
\hline Male & 575 & Reference & \\
\hline Female & 750 & $0.985(0.412-.356)$ & 0.973 \\
\hline Suicide Method & & & 0.113 \\
\hline Violent (Hanging/ Burning) & 435 & Reference & \\
\hline Non Violent (Poisioning or Oerdose) & 890 & $2.025(0.846-4.852)$ & \\
\hline
\end{tabular}


drowning, railway deaths and self-immolation are observed in Asian countries which are absent in another region of the world (Wu et al., 2012) .In the present study poisoning, self immolation and hanging were the three most common suicide methods. Male predominance was observed in poisoning (nonviolent suicide method) while female predominance in Self immolations (violent suicide method) the same observation was also reported by a previous studies (Sharma et al., 2007; Kanchan et al., 2009; Jaiprakash et al., 2011). In rural region of India women have access to combustion fuels i.e. kerosene, petrol etc. which are commonly used in cooking with stoves while males predominantly engaged in agricultural activities have easy access to Pesticides and other agrochemicals therefore self immolation is common among females while Pesticide poisoning among males. Self immolation has sociocultural root, in ancient India Jauhar (Rajput women along with their children would end life in a mass suicide in order to escape aftermath atrocities of a lost war) and Sati (self-immolation of the widow in the pyre of her husband or after the cremation of the husband' (Vijayakumar, 2004). Hence it could be deduced that in Indian context the preference of suicide method is usually governed by availability, accessibility and socio acceptability rather than violence associated with lethality of method (Kanchan et al., 2009) .

Out of the various poisons, pesticide was the most preferred poison, this observation is accordance with earlier studies conducted in India (Patel et al., 2012; Gajalakshmi \& Peto, 2007; Joshi et al., 2015; Bose et al., 2009). Pesticide self Poisoning accounts for $30 \%$ suicide globally and 20\% Suicides in Southeast Asia (Gunnell et al., 2007) to which WHO launched has Global Pesticide and Health Initiative recommending new pesticide policy, conducting epidemiological surveillance, developing programs to minimize pesticide poisoning and medical management of pesticide poisoning (WHO Official website, 2018b). The promising approach to curtailing pesticide suicide mortality includes withdrawal of more toxic pesticide (Zalsman et al., 2016). Further reduced accessibility and safer storage of pesticides in Communal storage centers (Zalsman et al., 2016) would be effective as in India as in majority of self poisoning cases, poisons are obtained in or vicinity of home (Bose et al., 2009). Supervasmol $33^{\mathrm{max}}$ an inexpensive hair dye, has emerged as a common suicide method popular among housewives (Chrispal et al., 2010) and the same was also observed in the present study. Public awareness on potential toxicity and proper toxicity warnings on hair dye packets could be initiated as preventive strategies (Chrispal et al., 2010) . Another notorious category are poisonous plant such as Yellow Oleander (Thevelia peruvianna) and Cleisthus collinus (oduvanthalia) which are also reportedly consumed for self harm in South
India (Bose et al., 2009) and if poison is not detected or diagnosed the antdote could not be administered resulting in fatality.

Seasonality in Suicide is reported from studies conducted around the globe (Naidoo \& Schlebusch, 2014; Jia \& Zhang, 2011; Dias et al., 2014) and the same was also observed in the present study. Hence suicide prevention strategies such as restriction of access to suicide methods, screening of risk population and strengthening of current medical emergency interventions could be initiated during the hotspot seasons of suicide. The hypothesis proposed to explain Suicide seasonality includes Biopsychiatric approach according to which seasonality in suicide are attributed seasonal affective disorders or due to the affect weather variables on neuroendocrine cycles (Ajdacic-Gross et al., 2010). Further according to the Social Psychological approach, suicide seasonality is determined by the intensity of the Social activity or could be due to failure to meet heightened expectations ahead of new cycle of year or simply by the opportunity to access of the means of suicide example seasonal agricultural activity in rural region increases the opportunity to access Pesticide (AjdacicGross et al., 2010).

\section{Conclusions}

The study highlights differential vulnerable age, suicide methods and seasonality of violent suicide across the two genders. These observations could be taken in account for formulating or strengthening existing suicide preventions strategies.

\section{Acknowledgements}

The authors are thankful to Mahatma Gandhi Memorial Hospital (MGM) hospital for providing the data. We are also thankful to Mr. Chakraverti Mahajan (Assistant professor, Department of Anthropology) for his valuable suggestions and critical evaluation of the present manuscript.

\section{Funding}

Not applicable

\section{Availability of data and materials \\ The data used and analyzed in this study are available from the corresponding author on reasonable request.}

\section{Authors' contributions}

The study was conceptualized by KNS and SR. Secondary data was collected and analyzed by SR. The statistical analysis was performed and interpreted under the supervision of MAK. The manuscript was drafted by SR and all critical revision in the manuscript was done by KNS and PCJ. All authors read and approved the final manuscript.

\section{Authors' information}

Suchita Rawat is a Ph.D. Research Scholar at Dept. Of Anthropology, University Of Delhi. Prof. Pooran Chand Joshi is Professor, Dept. Of Anthropology, University Of Delhi. Dr. Maroof Ahmad Khan is Associate Professor, Department of Biostatistics, All India Institute of Medical Sciences (AlIMS) New Delhi. Dr. Kallur Nava Saraswathy is Assistant Professor, Dept of Anthropology, University Of Delhi. 


\section{Ethics approval and consent to participate}

This study was approved by the Institutional Ethics Committee of the Kakatiya Medical College, Warangal.

\section{Consent for publication}

Not applicable

\section{Competing interests}

The authors declare that they have no competing interests.

\section{Publisher's Note}

Springer Nature remains neutral with regard to jurisdictional claims in published maps and institutional affiliations.

\section{Author details}

'Department of Anthropology, University of Delhi, Delhi 110007, India. ${ }^{2}$ Department of Biostatistics, All India Institute of Medical Sciences (AlIMS), New Delhi 110029, India.

Received: 6 July 2017 Accepted: 12 January 2018

Published online: 25 January 2018

\section{References}

Ajdacic-Gross V, Bopp M, Ring M, Gutzwiller F, Rossler W (2010) Seasonality in suicide-a review and search of new concepts for explaining the heterogeneous phenomena. Soc Sci Med 71(4):657-666

Ajdacic-Gross V, Weiss MG, Ring M, Hepp U, Bopp M, Gutzwiller F, Rössler W (2008) Methods of suicide: international suicide patterns derived from the WHO mortality database. Bull World Health Organ 86(9):726-732

Badiye A, Kapoor N, Ahmed S (2014) An empirical analysis of suicidal death trends in India: a 5 year retrospective study. J Forensic Legal Med 27:29-34

Batra AK (2003) Self immolation mortality: recent trends and sociocultural determinants in rural India. Self immolations 29(3):270-275

Bose A, Sandal Sejbaek C, Suganthy P, Raghava V, Alex R, Muliyil J, Konradsen F (2009) Self-harm and self-poisoning in southern India: choice of poisoning agents and treatment. Tropical Med Int Health 14(7):761-765

Census of India 2018 http://www.censusindia.gov.in/2011census/dchb/ ApBookA.htm

Chettri R, Gurung J, Singh B (2016) A 10-year retrospective study of suicide in Sikkim, India: sociodemographic profile and risk assessment. Indian J Psychiatry 58(4):448

Chrispal A, Begum A, Ramya I, Zachariah A (2010) Hair dye poisoning-an emerging problem in the tropics: an experience from a tertiary care hospital in South India. Trop Dr 40(2):100-103

Coimbra DG, e Silva ACP, de Sousa-Rodrigues CF, Barbosa FT, de Siqueira Figueredo D et al (2016) Do suicide attempts occur more frequently in the spring too? A systematic review and rhythmic analysis. J Affect Disord 196: 125-137

Dervic K, Amiri L, Niederkrotenthaler T, Yousef S, Salem MO, Voracek M, Sonneck $G$ (2012) Suicide rates in the national and expatriate population in Dubai, United Arab Emirates. Int J Soc Psychiatry 58(6):652-656

Dias D, Mendonça MC, Real FC, Vieira DN, Teixeira HM (2014) Suicides in the Centre of Portugal: seven years analysis. Forensic Sci Int 234:22-28

ElHak SAG, El-Ghazali AM, Salama MM, Aboelyazeed AY (2009) Fatal suicide cases in port said city, Egypt. J Forensic Legal Med 16(5):266-268

Gajalakshmi V, Peto R (2007) Suicide rates in rural Tamil Nadu, South India: verbal autopsy of 39000 deaths in 1997-98. Int J Epidemiol 36(1):203-207

Gunnell D, Eddleston M, Phillips MR, Konradsen F (2007) The global distribution of fatal pesticide self-poisoning: systematic review. BMC Public Health 7(1):357

Hawton K, Heeringen KN (2009) Suicide. Lancet 373:1372-1381

Jaiprakash H, Sarala N, Venkatarathnamma PN, Kumar TN (2011) Analysis of different types of poisoning in a tertiary care hospital in rural South India. Food Chem Toxicol 49(1):248-250

Jia CX, Zhang J (2011) Characteristics of young suicides by violent methods in rural China. J Forensic Sci 56(3):674-678

Joinpoint Regression Program, Version 4.5.0.1 - June 2017; Statistical methodology and applications branch, Surveillance Research Program, National Cancer Institute

Jordans MJ, Kaufman A, Brenman NF, Adhikari RP, Luitel NP, Tol WA, Komproe I (2014) Suicide in South Asia: a scoping review. BMC psychiatry 14(1):358
Joshi R, Guggilla R, Praveen D, Maulik PK (2015) Suicide deaths in rural Andhra Pradesh-a cause for global health action. Trop Med Int Health 20(2):188-193

Kanchan T, Menon A, Meneze RG (2009) Methods of choice in completed suicides: gender differences and review of literature. J Forensic Sci 54(4):938-942

Kumar S, Verma AK, Bhattacharya S, Rathore S (2013) Trends in rates and methods of suicide in India. Egyptian J Forensic Sci 3(3):75-80

Masango SM, Rataemane ST, Motojesi AA (2008) Suicide and suicide risk factors: a literature review: CPD. S Afr Family Pract 50(6):25-29

Menon V, Kattimani S, Sarkar S, Muthuramalingam A (2015) Gender differences among suicide attempters attending a crisis intervention Clinic in South India. Ind Psychiatry J 24(1):64

Mergl R, Koburger N, Heinrichs K, Székely A, Tóth MD, Coyne J, Värnik A (2015) What are reasons for the large gender differences in the lethality of suicidal acts? An epidemiological analysis in four European countries. PLoS One 10(7):e0129062

Mohanty BB (2013) Farmer suicides in India. Econ Polit Wkly 48(21):45-54

Mohanty S, Sahu G, Mohanty MK, Patnaik M (2007) Suicide in India-a four year retrospective study. J Forensic Legal Med 14(4):185-189

Naidoo SS, Schlebusch L (2014) Sociodemographic characteristics of persons committing suicide in Durban, South Africa: 2006-2007. Afr J Primary Health Care \& Family Med 6(1):1-7

National Crime Records Bureau of the Ministry of Home Affairs, Government of India, Report on Accidents and Suicides in India (2010-2015). 2018 http://ncrb.gov.in/ Accessed 1 May 2017

NDTV official website: 2018 https://www.ndtv.com/telangana-news/farmersuicides-telangana-hikes-compensation-from-rs-1-5-lakh-to-rs-6-lakh-1219527 Accessed 11 June 2017

Official website India today: 2018 http://indiatoday.intoday.in/story/osmaniauniversity-student-suicide-telangana-state/1/280349.html Accessed 1 June 2016

Official website Newyork times. 2018 http://www.nytimes.com/2010/03/31/world/ asia/31india.html Accessed 1 June 2016

Patel V, Ramasundarahettige C, Vijayakumar L, Thakur JS, Gajalakshmi V, Gururaj G, Million Death Study Collaborators (2012) Suicide mortality in India: a nationally representative survey. Lancet 379(9834):2343-2351

Phillips MR, Cheng HG (2012) The changing global face of suicide. Lancet 379(9834):2318

Rao GP, Math SB, Raju MSVK, Saha G, Jagiwala M, Sagar R, Rao TS (2016) Mental health care bill, 2016: a boon or bane? Indian J Psychiatry 58(3):244

Sharma BR, Gupta M, Sharma AK, Sharma S, Gupta N, Relhan N, Singh H (2007) Suicides in northern India: comparison of trends and review of literature. J Forensic Legal Med 14(6):318-326

Sun J, Guo X, Zhang J, Jia C, Xu A (2013) Suicide rates in Shandong, China, 1991 2010: rapid decrease in rural rates and steady increase in male-female ratio. J Affect Disord 146(3):361-368

Sun SH, Jia CX (2014) Completed suicide with violent and non-violent methods in rural Shandong, China: a psychological autopsy study. PLoS One 9(8):e104333

Vijayakumar L (2004) Altruistic suicide in India. Arch of Suicide Res 8(1):73-80

WHO Official website 2018a http://www.who.int/mediacentre/factsheets/fs398/ en/ Accessed 1 May 2017

WHO Official website 2018b http://www.who.int/mental_health/prevention/ suicide/pesticides/en/ Accessed 11 June 2017

World Health Organization. Preventing suicide: A global imperative. 2014. URL: http://www.who.int/mental_health/suicide-prevention/world_report_2014/ en/. Accessed 1 May 2017

Wu KCC, Chen YY, Yip PS (2012) Suicide methods in Asia: implications in suicide prevention. Int J Environ Res Public Health 9(4):1135-1158

Zalsman G, Hawton K, Wasserman D, van Heeringen K, Arensman E, Sarchiapone M, Purebl G (2016) Suicide prevention strategies revisited: 10-year systematic review. The Lancet Psychiatry 3(7):646-659 